\title{
INFORMES
}

\section{LAS CATEGORİAS DEL ESTADO CIVIL EN LOS CENSOS DE POBLACIÓN MEXICANOS}

\author{
Clara Jusidman de Bialostozky \\ Et Colegio de México
}

\begin{abstract}
El trabajo que se presenta a continuación es una versión ampliada de otro presentado ante êl Consejo Técnico de la Dirección General de Estadística, con objeto de fundamentar la modificación de las categorías del estado civil y sus definiciones para fines censales.

En años recientes ha habido una gran evolución y un creciente interés en la investigación demográfica. Dado que los Censos de Población, levantados en México cada diez años, constituyen una de las fuentes estadísticas básicas para la realización de dichas investigaciones, se considera de suma importancia la revisión constante de los conceptos en ellos incluidos, de tal modo que se ajusten en forma más adecuada a las necesidades de análisis.

Las modificaciones sugeridas a continuación respecto a las categorías del estado civil permitirán analizar y conocer, en forma más apegada a la realidad, el comportamiento y las características de los distintos grupos de individuos según categorías del estado civil; especialmente en cuanto a su estructura por edades y sexo, su comportamiento ante la fecundidad y su participación en la actividad económica.

Un segundo objetivo del trabajo es tratar de demostrar el efecto que pueden tener en los resultados obtenidos $\mathrm{y}$, por lo tanto, en los análisis derivados de éstos, clasificaciones y definiciones de conceptos incompletas y deficientes. Creemos que una actitud sana de todo investigador debería ser el tratar de conocer las definiciones utilizadas en los conceptos captados, así como el contenido de las clasificaciones manejadas, con objeto de descartar la posibilidad de que ciertos cambios o tendencias observados en los datos sean resultado de cambios en las definiciones, heterogeneidad en los grupos de las clasificaciones, etc.
\end{abstract}

\section{Definiciones y clasificaciones del estado civil}

Según Naciones Unidas, el estado civil es "la situación de la persona empadronada en relación con las leyes o costumbres matrimoniales del país". Se recomienda obtener información por lo menos, de las siguientes categorias: a) solteros, es decir, que nunca han contraído matrimonio; $b$ ) casados; $c$ ) viudos que no han vuelto a contraer matrimonio; $d$ ) divorciados que no han vuelto a contraer matrimonio, y e) casados pero separados legalmente.1

En el caso de México es posible hacer dos clasificaciones de las categorías del estado civil:

1) Una que tome en cuenta exclusivamente las situaciones del estado

1 Naciones Unidas, Principios y recomendaciones relativos a los censos de población de 1970, Nueva York, 1967, p. 47. 
civil de derecho, es decir, aquellas relacionadas sólo con las leyes matrimo. niales del país. Sería la siguiente:
a) soltero
b) casado por lo civil
c) divorciado legalmente
d) separado legalmente
e) viudo de matrimonio sivil.

2) Otra clasificación que considere las categorías del estado civil de hecho, o sea, que incluya tanto las relaciones con las leyes como con las costumbres matrimoniales.2 A continuación se listan éstas:
a) soltero
b) casado por lo civil
c) casado por la religión
d) casado por lo civil y la religión
e) divorciado de matrimonio civil
f) divorciado de matrimonio religioso
g) divorciado de matrimonio civil y religioso
h) separado legalmente de matrimonio civil
i) separado de hecho de matrimonio civil
j) separado de hecho de matrimonio religioso
$k$ ) separado de hecho de matrimonio civil y religioso
l) viudo de matrimonio civil
$m$ ) viudo de matrimonio religioso
n) viudo de matrimonio civil y religioso
o) vive en unión libre
p) separado de unión libre
q) viudo de unión libre.

Las categorías $a, b, e, h$ y $l$ son estados de derecho; $c, f, i, j, m, o, p$ y $q$ son situaciones de hecho, y por último, $d, g, k$ y $n$ son combinaciones de una situación de hecho y otra de derecho.

Las categorías usadas en el Censo de Población efectuado en 1960 son las siguientes: $:$

a) Soltero - persona que nunca ha estado casada y que en la fecha del censo no vive en unión libre.

b) Casado por lo civil —cuando la persona declare que está casada por lo civil.

c) Casado por la iglesia -cuando la persona declare que está unida en matrimonio religioso.

d) Casado por lo civil y por la iglesia - cuando la persona está casada en matrimonio civil y también en matrimonio religioso.

e) Unión libre -cuando la persona declare vivir maritalmente con otra persona, sin haber contraído matrimonio civil ni religioso.

f) Viudo - se considera como tal a la persona que habiendo perdido por fallecimiento a su cónyuge (con quien estaba casada civil o religiosamente), no ha vuelto a contraer matrimonio ni vive en unión libre.

g) Divorciado legalmente - cuando la persona declare estar divorciada, esto es, que su matrimonio quedó disuelto por sentencia firme de divorcio

2 En este caso sería más correcto hablar de "estado o situación conyugal" que de "estado civil".

3 Dirección General de Estadística, Instructivo para el llenado de la boleta del 8o. Censo General de Población, México, 1960. pp. 22-23. 
dictada por autoridades competentes, y que no se ha vuelto a casar, ni vive en unión libre.

Estas categorías han sido utilizadas a partir del Censo de 1930 y sus definiciones, en términos generales, han sido las mismas.

Como se puede observar, esta clasificación incluye dos estados conyugales de hecho (el matrimonio por la iglesia y la unión libre), un estado que es combinación de una situación de hecho y otra de derecho (matrimonio civil y por la iglesia); en cambio, deja de tener en cuenta una situación de derecho (separación legal) y el resto de los estados de hecho.

Además, tienen preferencia las situaciones de derecho, pues si la persona no declara vivir en el momento del censo en unión libre, siempre se encontrará en una categoría de derecho. Es decir, no se consideran las posibilidades de disolución de la unión libre y, por lo tanto, el haber vivido en unión libre anteriormente. Por ejemplo, una persona que estuvo viviendo en unión libre con otra durante veinte años, pero que perdió a su cónyuge por fallecimiento o por separación, aparecerá como soltera.

Una de las razones de esta situación es la dificultad de definir la unión libre. Esta dificultad se ha tratado de subsanar en ocasiones dándole a la unión libre cierto carácter de estabilidad o permanencia al hablarse de "vivir maritalmente con otra persona" o bien, "viven como si fueran marido y mujer".

Por lo tanto, los separados de cualquier tipo de unión y los viudos de unión libre, de acuerdo con las instrucciones censales, aparecerán en su estado de derecho anterior a su situación actual. Probablemente irán a abultar el número de solteros.

La anulación del matrimonio religioso tampoco está claramente ubicada, pero dado que su frecuencia es probablemente muy baja y que las personas que se divorcian tanto por lo civil como por la religión se incluyen en el grupo de "divorciados legalmente" podemos considerarlo como un problema menor.

\section{Algunos efectos de la clasificación de estado civil en el análisis demográfico}

El hecho de que la clasificación mexicana no considere solamente las situaciones conyugales de derecho, pero tampoco incluya la totalidad de los estados de hecho, afecta lo siguiente:

1) El volumen total de personas en cada categoría del estado civil.-Al incluirse tres situaciones de hecho (el matrimonio religioso, la unión libre y la viudez de matrimonio religioso) se produce una disminución en el volumen total de personas en cada una de las categorías de derecho, pues las personas que se declaran dentro de alguna de esas tres situaciones tienen además, un estado de derecho.

Por otro lado, la falta de ubicación clara de algunas categorías podría estar produciendo el abultamiento observado en la categoría de estado civil "no indicado", que en 1950 representó al $4.65 \%$ de la población considerada y en 1960 el 2.90.

En el cuadro 1 se puede observar este fenómeno, especialmente en las mujeres a partir de los 50 años y en los hombres, desde los 60 .

$\mathrm{La}$ tendencia observada en las edades más avanzadas puede deberse, en parte, a la posibilidad de mayores errores de declaración, pero también a la más alta probabilidad de que estas personas hubiesen pasado por una situación de unión libre. Existe una tendencia decreciente a la participación relativa de este tipo de unión en el total, de $13.91 \%$ en 1940 a 11.92 en 1950 y 9.47 en 1960 . 


\section{Cuadro 1}

ESTADO CIVIL "NO INDICADO", 1960

(Porciento en relación con el total de personas en el grupo de edad respectivo)

\begin{tabular}{lcc}
\hline Grupos de edad & Hombres & Mujeres \\
\hline Total & 2.87 & 2.91 \\
14 a 19 a & - & 2.86 \\
16 a 19 a & 2.82 & - \\
20 a 24 & 4.22 & 3.36 \\
25 a 29 & 3.06 & 2.89 \\
30 a 34 & 2.55 & 2.64 \\
35 a 39 & 2.27 & 2.39 \\
40 a 44 & 2.15 & 2.38 \\
45 a 49 & 1.93 & 2.27 \\
50 a 54 & 2.09 & 2.56 \\
55 a 59 & 2.01 & 2.61 \\
60 a 64 & 2.77 & 3.27 \\
65 a 69 & 2.42 & 3.45 \\
70 a 74 & 3.64 & 4.43 \\
75 a 79 & 3.29 & 3.99 \\
80 a 84 & 5.82 & 5.36 \\
85 o más & 1.82 & 2.76 \\
Edad no indicada & 12.18 & 13.46 \\
\hline
\end{tabular}

Fuente: Elaboración en base al cuadro 9 del VIII Censo General de Población.

a Se considera la población masculina a partir de los 16 años y la femenina a partir de los 14.

2) La estructura por edades de algunas categorías. - Una de las categorías más afectadas en su estructura por edades es la de solteros.

La proporción de solteros al aumentar la edad debe ir disminuyendo con respecto al total de personas en cada grupo de edad, como consecuencia de los casamientos y las uniones libres. "Esta disminución se va retardando en las edades maduras en las cuales son raras las constituciones de nuevas uniones conyugales y tiende a cesar en las edades seniles." 4

"Ésta es la marcha tendencial que se observa en las poblaciones cuyos censos clasifican exclusivamente el estado conyugal de derecho, siendo raras las uniones libres. En esas poblaciones no puede ocurrir que una persona vuelva a la categoría de soltero después de salir de ella (excepto en el caso rarísimo de anulación de casamiento). Sin embargo, en las poblaciones donde son frecuentes las uniones libres y en cuyos censos se clasifica a los amancebados, a menudo acontece que, después de la disolución de la unión libre, por ruptura o por el fallecimiento de uno de los amancebados, el otro declara el estado conyugal de soltero, que es efectivamente su estado de derecho y además, es la declaración que le cumple rendir de acuerdo con las instrucciones censales."

"Estos retornos al celibato pueden determiñar sensibles aumentos en las proporciones de los solteros en las edades maduras y seniles..."

4 Las citas que se hacen a continuación son de: G. Mortara, Características de la estructura demográfica de los paises americanos, Washington, D. C., Unión Panamericana, 1964, pp. 80-81. 


\section{Cuadro 2}

SOLTEROS POR 100 HABITANTES EN LOS GRUPOS DE EDAD RESPECTIVOS, POR SEXO

\begin{tabular}{|c|c|c|}
\hline Grupos de edad & Hombres & Mujeres \\
\hline 14 a 19 & 一 & 78.99 \\
\hline 16 a 19 & 90.41 & - \\
\hline 20 a 24 & 57.03 & 34.56 \\
\hline 25 a 29 & 27.26 & 17.85 \\
\hline 30 a 34 & 15.00 & 12.16 \\
\hline 35 a 39 & 10.19 & 9.64 \\
\hline 40 a 44 & 7.82 & 8.86 \\
\hline 45 a 49 & 6.58 & 8.30 \\
\hline 50 a 54 & 6.02 & 8.69 \\
\hline 55 a 59 & 5.51 & 8.61 \\
\hline 60 a 64 & 5.20 & 9.13 \\
\hline 65 a 69 & 5.01 & 9.51 \\
\hline 70 a 74 & 5.07 & 9.64 \\
\hline 75 a 79 & 5.08 & 9.89 \\
\hline 80 a 84 & 4.86 & 9.70 \\
\hline 85 o más & 4.72 & 9.01 \\
\hline No indicada & 18.22 & 13.64 \\
\hline
\end{tabular}

En el caso de México en 1960 se observa lo anterior, especialmente en Ias mujeres en donde después de bajar la proporción de solteras con respecto del total de mujeres en cada grupo de edad hasta $8.30 \%$ en el grupo 45 a 49, empieza a subir a partir de los 50 años (véase el cuadro 2). Este fenómeno no se observa en el caso de los hombres probablemente por la mayor propensión de éstos a volverse a casar o a unir.

3) Efecto en el cálculo de las tablas de nupcialidad.-Es posible hacer el cálculo de las tablas de nupcialidad del mismo modo que las tablas de vida activa, es decir, afectando las tablas por las salidas de la actividad, en este caso por la salida del estado conyugal.

Con la información existente sólo es posible afectar la tabla por salidas debidas a muerte (por medio de las tablas de mortalidad), por la desaparición legal de los vínculos matrimoniales (divorcio legal) y por la muerte del cónyuge de matrimonio civil y/o religioso. Si en la tabla se está incluyendo tanto a la población unida por cualquier tipo de matrimonio como a la que vive en unión libre, dada la clasificación de estado civil, no es posible afectar las tablas por las salidas motivadas por la desaparición de la unión libre surgidas de la separación o muerte del compañero o compañera.

4) Efecto en las curvas de actividad por estado civil-_Las curvas de actividad por estado civil también se verán afectadas. Nuevamente la más afectada será la curva de las solteras. El sesgo puede ser hacia el aumento de las tasas de actividad en las edades maduras, en los casos en que las cargas familiares de las separadas y las viudas de unión libre las obliguen a reingresar a la actividad económica o a permanecer en ella para el mantenimiento de sus familias, sobre todo por la falta de protección legal a que están sujetas. 
O bien el sesgo puede ser hacia una baja en las tasas de actividad en las edades maduras y seniles, si predominan los casos en que la mujer saparada o viuda de unión libre no se ve obligada a volver o a permanecer en la actividad puesto que sus hijos se encuentran ya trabajando, o porque no tienen cargas familiares.

Es más probable que dado los estratos económicos en donde se presenta con mayor frecuencia la unión libre, el primer sesgo sea el que más pese, especialmente en las edades de las mujeres en que todavía sus hijos son menores de edad.

Es un poco más difícil ver el efecto de la heterogeneidad de la definición de los grupos de estado civil en las curvas de actividad de los hombres puesto que en estos casos es probable que las diferencias de las curvas de actividad por estado civil sean reducidas; además, en general, la participación en la actividad no se verá fuertemente afectada por cambios en el estado civil del individuo.

5) Efecto en el número de hijos de las mujeres.-El número de hijos nacidos vivos promedio de las mujeres solteras y el número de mujeres solteras con hijos también se verán aumentados especialmente en las edades maduras y seniles, por la inclusión dentro de ese estado civil de algunas mujeres separadas y viudas de unión libre.

Todo lo anterior sería más notorio si no existiesen desviaciones en las respuestas, puesto que con cierta frecuencia los viudos o viudas de una unión libre se declararán como viudos y no como solteros o por el estado que tenían antes de unirse, que sería la declaración que les corresponde rendir de acuerdo con las definiciones dadas. "Es decir que se amplía el volumen de viudas, por la adición de muchas mujeres que no tienen derecho a esa clasificación."

No se cuenta con información que permita probar lo señalado en los dos últimos puntos, puesto que la información censal respecto al estado civil se limita a proporcionar información cruzada con sexo y edad. Sin embargo, la posibilidad cada vez mayor de extraer muestras de la información censal con miras a profundizar en el análisis de ciertos aspectos, así como el interés de proporcionar mayor información en las publicaciones censales, permiten prever mayores cruzamientos de la información sobre estado civil.

\section{Propuestas}

A continuación se incluye una proposición para agregar algunas categorías a la clasificación mexicana y para ampliar la definición de otras, quedando la clasificación del siguiente mođo:

1. Casada por lo civil y por la iglesia -aquella persona que ha contraído matrimonio por las leyes civiles y por alguna religión y que vive con su cónyuge, es decir, que no ha enviudado, ni se ha divorciado o separado.

2. Casada sólo por lo civil -aquella persona que ha contraido matrimonio sólo por la ley y que vive con su cónyuge, es decir, que no ha enviudado, ni se ha divorciado o separado.

3. Casada por la religión -es la que ha contraído matrimonio solamente por los preceptos establecidos por cualquier religión y que vive con su cónyuge, es decir, que no ha enviudado, ni ha anulado su matrimonio, ni se ha separado.

4. Vive en unión libre -es aquella persona que vive con otra como si estuviera casada sin haber contraído matrimonio civil o religioso. 
5. Viuda -es aquella persona que ha perdido a su esposo(a) o compañero(a) por fallecimiento y no se ha vuelto a casar ni a vivir en unión libre.

6. Divorciada - es aquella persona que, habiendo estado casada por lo civil, se separó mediante sentencia de divorcio dictada por la autoridad competente, o cuyo matrimonio religioso ha sido anulado, y que no se ha vuelto a casar ni a vivir en unión libre.

7. Separada - es aquella persona que vive separada de su esposo(a) o compañero(a) después de haber estado casada o haber vivido con otra persona como si estuviera casada.

8. Soltera -es la persona que nunca se ha casado y nunca ha vivido con otra persona como si estuviera casada.

Como se puede ver en las definiciones anteriores, se trata de la situación conyugal de la persona en el momento de levantarse el censo o la encuesta. Es decir, la situación en relación con la persona con la que vive en ese momento, o si no vive con nadie, la situación con respecto a la persona con la que estuvo unida la última vez. Obviamente, si no ha establecido relación conyugal alguna en el transcurso de su vida, se anotará como soltera.

Se considera que en todo trabajo de recolección estadística es necesario ser congruente y sisstemático en los planteamientos. Se debe tratar de limitar al máximo los sesgos a aquéllos derivados de malas declaraciones que, en la mayoría de los casos, están fuera del control del encargado de la recolección. 